Research Paper

\title{
Accuracy of Tissue and Sonication Fluid Sampling for the Diagnosis of Fracture-Related Infection: A Systematic Review and Critical Appraisal
}

\author{
Jolien Onsea1, Melissa Depypere², Geertje Govaert ${ }^{3}$, Richard Kuehl' ${ }^{4}$, Thomas Vandendriessche5, Mario \\ Morgenstern ${ }^{6}$, Martin McNally ${ }^{7}$, Andrej Trampuz ${ }^{8}$, Willem-Jan Metsemakers ${ }^{1}$ \\ 1. Department of Trauma Surgery, University Hospitals Leuven, Belgium \\ 2. Department of Laboratory Medicine, University Hospitals Leuven, Belgium \\ 3. Department of Trauma Surgery, University Medical Center Utrecht, The Netherlands \\ 4. Department of Infectious Diseases and Hospital Epidemiology, University Hospital of Basel, Switzerland \\ 5. KU Leuven Libraries - 2Bergen - Learning Centre Désiré Collen, Leuven, Belgium \\ 6. Department of Orthopaedic and Trauma Surgery, University Hospital Basel, Switzerland \\ 7. The Bone Infection Unit, Nuffield Orthopaedic Centre, Oxford University Hospitals, Oxford, United Kingdom \\ 8. Charité - Universitätsmedizin Berlin, corporate member of Freie Universität Berlin, Humboldt-Universität zu Berlin, and Berlin Institute of Health, Center \\ for Musculoskeletal Surgery
}

$\square$ Corresponding author: Willem-Jan Metsemakers, MD, PhD, Department of Trauma Surgery, University Hospitals Leuven, Herestraat 49 , 3000 Leuven, Belgium. Email: willem-jan.metsemakers@uzleuven.be; Phone: +32 16342041

(c) Ivyspring International Publisher. This is an open access article distributed under the terms of the Creative Commons Attribution (CC BY-NC) license (https://creativecommons.org/licenses/by-nc/4.0/). See http://ivyspring.com/terms for full terms and conditions.

Received: 2018.06.12; Accepted: 2018.08.01; Published: 2018.08.10

\begin{abstract}
Introduction: Intraoperatively obtained peri-implant tissue cultures remain the standard for diagnosis of fracture-related infection (FRI), although culture-negative cases may complicate treatment decisions. This paper reviews the evidence on sonication fluid and tissue sampling for the diagnosis of FRI.

Methods: A comprehensive search in Pubmed, Embase and Web-of-Science was carried out on April 5, 2018, to identify diagnostic validation studies regarding sonication fluid and tissue sampling for FRI.

Results: Out of 2624 studies, nine fulfilled the predefined inclusion criteria. Five studies focused on sonication fluid culture, two on PCR and two on histopathology. One additional histopathology study was found after screening of reference lists. There is limited evidence that sonication fluid culture may be a useful adjunct to conventional tissue culture, but no strong evidence that it is superior or can replace tissue culture. Regarding molecular techniques and histopathology the evidence is even less clear. Overall, studies had variable 'gold standard' criteria for comparison and poorly reported culture methods.

Conclusions: Scientific evidence on sonication fluid and tissue sampling, including culture, molecular techniques and histopathology for the diagnosis of FRI is scarce. It is imperative that laboratory protocols become standardized and uniform diagnostic criteria, as recently published in a consensus definition, be implemented.
\end{abstract}

Key words: Fracture-related infection, histopathology, sonication, tissue sampling, diagnosis, systematic review

\section{Introduction}

Approximately $14 \%$ of all trauma admissions suffer from at least one complication [1]. The incidence of infectious complications that involve a fracture, i.e. fracture-related infection (FRI), can range from 1 to $2 \%$ after internal fixation of closed fractures, up to $30 \%$ after open fractures $[2,3]$. FRI can have 
serious consequences, with impairment of patient function and even amputation of the affected limb [4]. Regarding treatment of FRI, one of the most difficult hurdles to tackle is the presence of a biofilm [2]. Bacteria attach to the surface of the orthopaedic implant or fracture fixation device and produce extracellular matrix, making them inaccessible to the host immune system as well as to most antibiotic drugs [2]. To increase the probability of successful treatment, an early and accurate diagnosis is of utmost importance [5].

Although these issues are well known, studies solely focusing on FRI are scarce, and therefore current diagnostic and treatment concepts for FRI are primarily based on those for prosthetic joint infection (PJI) [2]. Although there are similarities, important distinctions should be made between FRI and PJI, with the presence of a fracture and soft tissue damage being the most important [2]. Multiple definitions are available for PJI [6, 7]. For FRI, a consensus definition was recently proposed, utilizing two levels of certainty around diagnostic features: confirmative and suggestive [8]. Two of the four confirmatory (diagnostic) criteria are: phenotypically indistinguishable pathogens identified by culture from at least two separate intraoperative tissue or implant (sonication) specimens and the presence of microorganisms in intraoperative tissue taken during an operative intervention, as confirmed by histopathological examination. Deep tissue cultures, obtained from intraoperative samples remain the gold standard for diagnosis. Data on other techniques such as culture of sonication fluid from hardware, PCR and histopathology (i.e. presence of polymorphonuclear neutrophils (PMN's)) are less clear with respect to the diagnosis of FRI $[2,8]$.

This systematic review provides an overview of validation studies regarding sonication fluid cultures, molecular techniques and histopathology as diagnostic criteria for FRI. The main hypothesis is that data focusing on these techniques in FRI is limited and well-designed, prospective clinical studies are necessary to improve our knowledge regarding this topic.

\section{Methods}

On April 5, 2018, with the help of a biomedical reference librarian (TV), a comprehensive literature search was performed in Embase, Pubmed and Web-of-Science. The methodology of this study was written following the Preferred Reporting Items for Systematic Reviews and Meta-Analyses (PRISMA) statement. Only articles in English, French or German language were included. The search strings are attached as supplementary material. Two reviewers
(JO and WJM) screened all articles and in case of indecision a third reviewer was consulted (MD). Articles were first screened on title and abstract after which the full-texts of the included articles were reviewed. Studies looking into both PJI and FRI were also included. A detailed description of eligibility criteria is listed in Table 1.

Table 1. Detailed eligibility criteria for the systematic review.

\begin{tabular}{|c|c|c|}
\hline & Inclusion criteria & Exclusion criteria \\
\hline $\begin{array}{l}\text { Target } \\
\text { population }\end{array}$ & $\begin{array}{l}\text { Patients who suffered } \\
\text { musculoskeletal trauma of the long } \\
\text { bones and consequently developed } \\
\text { FRI }\end{array}$ & $\begin{array}{l}\text { Studies limited to patients } \\
\text { with PJI } \\
\text { Animal studies } \\
\text { Spine studies }\end{array}$ \\
\hline Tests & $\begin{array}{l}\text { Sonication fluid tests } \\
\text { Sonication fluid culture } \\
\text { Sonication fluid PCR } \\
\text { Sonication fluid Gram's stain } \\
\text { Peri-implant tissue tests } \\
\text { Tissue cultures } \\
\text { Molecular methods } \\
\text { PCR } \\
\text { Fluorescent in situ hybridization } \\
\text { (FISH) } \\
\text { Histopathology }\end{array}$ & $\begin{array}{l}\text { Serum marker tests } \\
\text { Imaging modalities }\end{array}$ \\
\hline $\begin{array}{l}\text { Types of } \\
\text { study }\end{array}$ & $\begin{array}{l}\text { Validation studies: original research } \\
\text { papers assessing } \\
\text { Sensitivity and specificity of tests } \\
\text { Positive predictive value (PPV) and } \\
\text { negative predictive value (NPV) of } \\
\text { tests }\end{array}$ & $\begin{array}{l}\text { Case reports, reviews, } \\
\text { language other than } \\
\text { English, French or } \\
\text { German, no full-text, } \\
\text { poster presentations, } \\
\text { conference papers, } \\
\text { commentaries, expert } \\
\text { opinions, articles older } \\
\text { than 1990, studies } \\
\text { evaluating cultures } \\
\text { obtained during open } \\
\text { fracture management } \\
\text { studies }\end{array}$ \\
\hline
\end{tabular}

\section{Results}

A total of 10 validation studies corresponded to the eligibility criteria (Fig. 1). Of these studies, five focused on sonication fluid culture [9-13], two on PCR of either tissue swabs or sonication fluid [14, 15], and three on histopathology [16-18]. One of the sonication studies [13] investigated various diagnostic modalities, including histopathology. One of the PCR studies included sonication fluid culture as well as histopathology [15]. No studies validating other diagnostic tests for sonication fluid or tissue samples (i.e. FISH) met the eligibility criteria displayed in Table 1.

\section{Sonication}

The studies evaluating the diagnostic value of sonication fluid cultures are summarized in Table 2. Most of these studies included both patients with prosthetic joints and patients with fracture fixation devices and, overall, referred to a PJI definition for infection [9, 11-13]. One study by Yano et al. focused on patients with fracture fixation devices, including spinal implants $(13.8 \%)$, and referred to a customized 


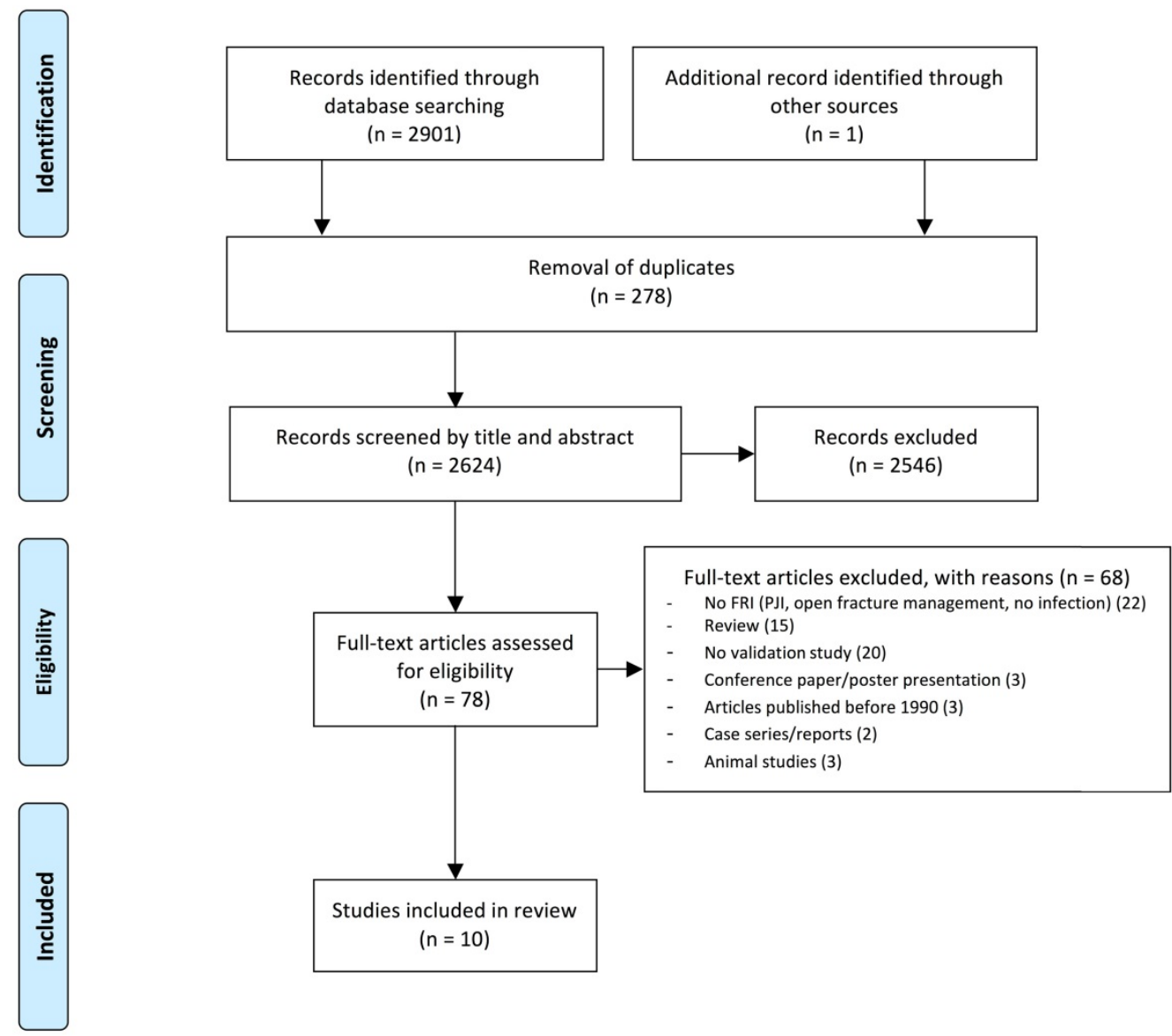

Figure 1. Flowchart of the systematic search and selection process following the PRISMA statement. FRI: Fracture-Related Infection.

definition for osteosynthesis-associated infection [10]. All studies used diagnostic criteria from the definition they provided as a reference to diagnose infection and all included tissue cultures as a comparator. Regarding incubation time and number of tissue samples taken, laboratory and sampling protocols differed between studies.

One study by Puig-Verdié et al. [9] could not detect a significant difference between sonication fluid culture and tissue culture for FRI patients. Six percent of patients in this study received antibiotics before surgery (antibiotics were stopped within 1 to 22 days prior to surgery). Fracture fixation devices were assessed separately from spinal implants in this study [9]. Yano et al. focused on osteosynthesisassociated infection and found a significantly higher sensitivity for sonication fluid culture compared to tissue culture. This difference could not be found for specificity. Overall, $31.2 \%$ of patients in this study received antibiotics within 14 days prior to the surgery [10]. A higher sensitivity rate was also found for sonication fluid cultures versus tissue cultures in the study by Portillo et al. However, this study did not assess test accuracy for fracture fixation devices separately from prostheses and did not specify which types of fixation material were included. Fifty-six percent of study subjects received antibiotics in the 14 days prior to surgery [11]. Three studies reported a sub-analysis on patients who received preoperative antibiotic treatment. Except for the study performed by Yano et al., all sub-analyses left the type of implant (i.e. prosthesis or fracture fixation device) out of consideration. For the subgroup of patients who received antibiotics at the time of sampling, all three studies concluded a higher sensitivity rate for sonication fluid cultures compared to intraoperative tissue cultures [9-11]. The studies by Esteban et al. [12] and Holinka et al. [13] did not assess fracture fixation devices separately from prostheses. Both studies had small sample sizes, Esteban et al. included 13 patients and Holinka et al. included 6 patients with fracture fixation devices. Esteban et al. did not report significance levels or number of patients receiving preoperative antibiotic therapy. This study found a low specificity rate $(50 \%)$ for sonication fluid cultures, which was attributed to possible contamination and or use of multiple culture media [12]. Holinka et al. did not provide overall sensitivity and specificity rates but reported them separately for patients who did or did not receive preoperative antibiotics. The 
authors compared sonication fluid cultures with Gram's stain of centrifuged sonication fluid, tissue cultures and histopathology. They concluded that the sensitivity of sonication fluid cultures was significantly higher than that of tissue cultures with two or more positive cultures yielding the same microorganism. In patients who received antibiotics preoperatively, no statistically significant difference was found between tissue cultures with two or more positive cultures yielding the same organism and sonication fluid cultures [13]. The study by Renz et al. [15], detailed in the molecular techniques section (Table 3), found no significant difference between the sensitivity of sonication fluid cultures (84\%) and the sensitivity of tissue cultures (66\%).

Table 2. Studies on sonication fluid culture of orthopaedic implants.

\begin{tabular}{|c|c|c|c|c|c|c|c|c|c|c|}
\hline Author & $\mathrm{N}_{\mathrm{T}}$ & $\mathrm{N}_{\text {Fix }}$ & Test & Sens (\%) & Spec (\%) & PPV (\%) & NPV (\%) & Reference criteria & Incubation time & $\begin{array}{l}\text { number of } \\
\text { tissue } \\
\text { samples }\end{array}$ \\
\hline \multirow[t]{2}{*}{$\begin{array}{l}\text { Puig-Verdié et al. } \\
2013\end{array}$} & \multirow[t]{2}{*}{317} & \multirow[t]{2}{*}{101} & SFC & 93,3 & 97,2 & 93,3 & 97,2 & \multirow{2}{*}{$\begin{array}{l}\text { Definition: PJI } \\
\text { Diagnostic criteria: } \\
\geq 1 \text { of the following: } \\
\text { Purulence synovial fluid or surrounding } \\
\text { implant } \\
\text { Sinus tract communicating with implant } \\
\text { Histopathology: acute inflammation ( } \geq 5 \\
\text { PMN's/HPF) } \\
\text { Positive culture (SFC or TC) with clinical signs }\end{array}$} & $\begin{array}{c}\text { Aerobe: } 7 \text { days } \\
\text { Anaerobe: } 7 \text { days }\end{array}$ & \\
\hline & & & $\mathrm{TC}$ & 76,7 & 100 & 100 & 91 & & $\begin{array}{l}\text { Aerobe: } 7 \text { days } \\
\text { Anaerobe: } 7 \text { days }\end{array}$ & 5 \\
\hline \multirow[t]{2}{*}{$\begin{array}{l}\text { Yano et al. } \\
2014\end{array}$} & \multirow[t]{2}{*}{180} & \multirow[t]{2}{*}{180} & SFC & 90,4 & 90,9 & 95,8 & 80,6 & \multirow{2}{*}{$\begin{array}{l}\text { Definition: customized definition for FRI } \\
\text { Diagnostic criteria: } \\
\geq 1 \text { of the following: } \\
\text { Open wound exposing fracture and/or } \\
\text { osteosynthesis with purulence } \\
\text { Intraoperative tissue with visible purulence } \\
\text { Draining fistula communicating with implant } \\
\text { Histopathology: acute inflammation in } \\
\text { intraoperative osteosynthesis tissue }\end{array}$} & $\begin{array}{l}\text { Aerobe: } 7 \text { days } \\
\text { Anaerobe: } 14 \text { days }\end{array}$ & \\
\hline & & & $\mathrm{TC}$ & 56,8 & 96,4 & 97,3 & 49,7 & & $\begin{array}{l}\text { Aerobe: } 7 \text { days } \\
\text { Anaerobe: } 14 \text { days }\end{array}$ & $>1$ \\
\hline \multirow[t]{3}{*}{$\begin{array}{l}\text { Portillo et al. } \\
2014\end{array}$} & \multirow[t]{3}{*}{75} & \multirow[t]{3}{*}{30} & SF-HC & 100 & 100 & 100 & 100 & \multirow{3}{*}{$\begin{array}{l}\text { Definition: PJI } \\
\text { Diagnostic criteria: } \\
\text { For FRI cases: } \geq 1 \text { of the following: } \\
\text { Purulence of site aspirate or at surgical site } \\
\text { Tract communicating with implant } \\
\text { Clinical infection signs } \\
\text { In addition, for PJI: } \\
\text { Histopathology: acute inflammation } \\
\text { Acute inflammation in preoperative joint } \\
\text { aspiration }\end{array}$} & $\begin{array}{l}\text { Aerobe: } 7 \text { days } \\
\text { Anaerobe: } 14 \text { days }\end{array}$ & \\
\hline & & & SFC & 87 & 100 & 100 & 88 & & $\begin{array}{l}\text { Aerobe: } 7 \text { days } \\
\text { Anaerobe: } 14 \text { days }\end{array}$ & \\
\hline & & & TC & 59 & 100 & 100 & 69 & & $\begin{array}{l}\text { Aerobe: } 7 \text { days } \\
\text { Anaerobe: } 14 \text { days }\end{array}$ & $\begin{array}{c}\text { not } \\
\text { mentioned }\end{array}$ \\
\hline \multirow[t]{2}{*}{$\begin{array}{l}\text { Esteban et al. } \\
2008\end{array}$} & \multirow[t]{2}{*}{31} & \multirow[t]{2}{*}{13} & SFC & 94,7 & 50 & 75 & 85,7 & \multirow[b]{2}{*}{$\begin{array}{l}\text { Definition: PJI } \\
\text { Diagnostic criteria: } \\
\geq 1 \text { of the following: } \\
\text { Fistula } \\
\text { Purulent wound discharge } \\
\text { Intraoperative periprosthetic purulence } \\
\text { Sinus tract communicating with prosthesis } \\
\text { Laboratory findings (CRP and ESR) } \\
\text { Radiological signs } \\
\text { Gamma scan findings }\end{array}$} & $\begin{array}{l}\text { Aerobe: } 7 \text { days } \\
\text { Anaerobe: } 7 \text { days }\end{array}$ & \\
\hline & & & $\mathrm{TC}$ & 84,2 & 100 & 100 & 81,8 & & no protocol provided & 3 to 5 \\
\hline \multirow{10}{*}{$\begin{array}{l}\text { Holinka et al. } \\
2010\end{array}$} & \multirow[t]{10}{*}{60} & 6 & SFC & & & & & \multirow{10}{*}{$\begin{array}{l}\text { Definition: PJI } \\
\text { Diagnostic criteria: } \\
\geq 1 \text { of the following: } \\
\geq 2 \text { cultures of joint aspirates or tissue cultures } \\
\text { yielding the same microorganism } \\
\text { Purulence surrounding the prosthesis } \\
\text { Histopathology: acute inflammation } \\
\text { Sinus tract communicating with prosthesis }\end{array}$} & Aerobe: 5 days & \\
\hline & & & AB- & 83,3 & 95 & 93,8 & 86,4 & & Anaerobe: 7 days & \\
\hline & & & $\begin{array}{l}\mathrm{AB}+ \\
\mathrm{TC} 1\end{array}$ & 65,9 & 94,7 & 96,4 & 56,3 & & & \\
\hline & & & AB- & 72,2 & 95 & 92,9 & 79,2 & & $\begin{array}{l}\text { Aerobe: } 5 \text { days } \\
\text { Anaerobe: } 7 \text { days }\end{array}$ & at least 3 \\
\hline & & & $\begin{array}{l}\mathrm{AB}+ \\
\mathrm{TC} 2\end{array}$ & 57,5 & 95 & 95,8 & 52,8 & & & \\
\hline & & & AB- & 61.1 & 95 & 91,7 & 73,1 & & & \\
\hline & & & $\begin{array}{l}\mathrm{AB}+ \\
\text { SF-GS }\end{array}$ & 42,5 & 95 & 94,4 & 45,2 & & & \\
\hline & & & AB- & 76,5 & 100 & 100 & 83,3 & & & \\
\hline & & & $\mathrm{AB}+$ & 55 & 100 & 100 & 52,6 & & & \\
\hline & & & $\mathrm{HP}$ & 95 & 100 & 100 & 99,9 & & & \\
\hline
\end{tabular}

Sensitivity and specificity are reported as they were calculated for all cases, without differentiating between cases who received preoperative antibiotics and those who did not receive antibiotics preoperatively, except for the study by Holinka et al, which did not provide overall values. $\mathrm{N}_{\mathrm{T}}$ : total number of study participants, $\mathrm{N}_{\mathrm{Fix}}$ : total number of participants with fracture fixation devices, Sens: sensitivity, Spec: specificity, PPV: positive predictive value, NPV: negative predictive value, PMN's: Polymorphonuclear neutrophils, HPF: high power field, SFC: sonication fluid culture, TC: tissue culture, TC1: single tissue culture, TC2: $\geq 2$ tissue cultures yielding the same microorganism, HC: hemoculture, SF-GS: Gram's stain from the centrifuged sediment of the sonication fluid, HP: histopathology, AB-: without preoperative antibiotics, AB+: with preoperative antibiotics, CRP: C-reactive protein, ESR: Erythrocyte sedimentation rate. 
Table 3. Data on the diagnostic performance of PCR.

\begin{tabular}{|c|c|c|c|c|c|c|c|c|}
\hline Author & $\mathrm{N}_{\mathrm{T}}$ & $\mathrm{N}_{\mathrm{fix}}$ & Test & Sens $(\%)$ & Spec $(\%)$ & PPV (\%) & NPV (\%) & Reference \\
\hline \multirow{2}{*}{$\begin{array}{l}\text { Omar et al. } \\
2016\end{array}$} & \multirow[t]{2}{*}{62} & \multirow[t]{2}{*}{62} & PCR & 69 & 64 & 90 & 30 & Definition: customized definition for FRI \\
\hline & & & $\mathrm{TC}$ & 92 & 82 & 96 & 69 & $\begin{array}{l}\text { Diagnostic criteria: } \\
\geq 1 \text { of the following: } \\
\text { Sinus tract or open wound communicating with the implant } \\
\text { Purulence encountered intraoperatively } \\
\text { Two out of three tissue cultures positive with the same pathogen }\end{array}$ \\
\hline \multirow[t]{4}{*}{ Renz et al. 2018} & \multirow[t]{4}{*}{51} & \multirow[t]{4}{*}{51} & SF-PCR & 71 & 92 & 96 & 52 & Definition: consensus definition for FRI \\
\hline & & & SFC & 84 & 100 & 100 & 68 & Diagnostic criteria: \\
\hline & & & $\mathrm{TC}$ & 66 & 100 & 100 & 40 & $\geq 1$ of the following: \\
\hline & & & $\mathrm{HP}$ & 74 & 100 & 100 & 33 & $\begin{array}{l}\text { Macroscopic purulence around the implant and/or presence of a sinus } \\
\text { tract communicating with the implant and/or implant on view } \\
\text { Presence of inflammation in peri-implant tissue, as defined by the } \\
\text { pathologist } \\
\text { Positive culture of peri-implant tissue or sonication fluid }\end{array}$ \\
\hline
\end{tabular}

$\mathrm{N}_{\mathrm{T}}$ : total number of study participants, $\mathrm{N}_{\mathrm{Fix}}$ : total number of participants with fracture fixation devices, Sens: sensitivity, Spec: specificity, PPV: positive predictive value, NPV: negative predictive value, TC: tissue cultures, SF-PCR: sonication fluid PCR, SFC: sonication fluid culture, HP: histopathology.

Table 4. Data on diagnostic performance of histopathology.

\begin{tabular}{|c|c|c|c|c|c|c|c|c|}
\hline Author & $\mathrm{N}_{\mathrm{T}}$ & Histopathology Criteria & Test & $\begin{array}{l}\text { Sens } \\
(\%)\end{array}$ & $\begin{array}{l}\text { Spec } \\
(\%)\end{array}$ & $\begin{array}{l}\text { PPV } \\
(\%)\end{array}$ & NPV $(\%)$ & Reference \\
\hline $\begin{array}{l}\text { Simpson et al. } \\
2002\end{array}$ & $\begin{array}{l}60 \text { ununited } \\
\text { fracture cases }\end{array}$ & $\begin{array}{l}\text { Highly suggestive: } \\
\text { >1 PMN/HPF on } \\
\text { average after } \\
\text { examination } \\
\text { of } 10 \mathrm{HPF} \\
\text { Definite infection: } \\
\text { Organisms seen on } \\
\text { Gram's staining }\end{array}$ & $\begin{array}{l}\text { Soft tissue } \\
\text { histopathology }\end{array}$ & 87 & 100 & 100 & 78 & $\begin{array}{l}\text { Definition: positive microbiological and } \\
\text { clinical diagnosis. } \\
\text { Microbiological diagnosis based on the } \\
\text { culture of } \geq 5 \text { deep specimens of tissue from } \\
\text { the non-union site. Positive result if at least } \\
\text { two separate specimens yielded the same } \\
\text { organism. } \\
\text { Clinical diagnosis: } \geq 1 \text { of the following: } \\
\text { Open wound or draining sinus } \\
\text { pre-operatively } \\
\text { Purulence encountered intraoperatively }\end{array}$ \\
\hline \multirow{2}{*}{$\begin{array}{l}\text { Chadayammuri } \\
\text { et al. } \\
2017\end{array}$} & \multirow{2}{*}{$\begin{array}{l}159 \text { cases with } \\
\text { post traumatic } \\
\text { osteomyelitis } \\
\text { of the long } \\
\text { bones }\end{array}$} & Not provided & $\begin{array}{l}\text { Soft tissue } \\
\text { histopathology }\end{array}$ & 69,8 & 38,9 & / & / & \multirow[t]{2}{*}{ Open bone biopsy and culture } \\
\hline & & & $\begin{array}{l}\text { Deep wound } \\
\text { swab culture }\end{array}$ & 66 & 28,1 & / & / & \\
\hline \multirow[t]{2}{*}{$\begin{array}{l}\text { Egol et al. } \\
2002\end{array}$} & \multirow{2}{*}{$\begin{array}{l}51 \text { cases with } \\
\text { delayed or } \\
\text { non-union }\end{array}$} & $\begin{array}{l}\text { Infected: } \\
\text { >10 PMN's/HPF }\end{array}$ & $\begin{array}{l}\text { Frozen section } \\
\text { histopathology }\end{array}$ & 0 & 98 & 0 & 88 & \multirow[t]{2}{*}{ Positive intraoperative tissue culture } \\
\hline & & $\begin{array}{l}\text { Not infected: } \\
\text { <5 PMN's/HPF } \\
\text { Equivocal: } \\
\text { 5-10 PMN's/HPF }\end{array}$ & $\begin{array}{l}\text { Permanent } \\
\text { section } \\
\text { histopathology }\end{array}$ & 33 & 95 & 50 & 91 & \\
\hline
\end{tabular}

$\mathrm{N}_{\mathrm{T}}$ : total number of study participants, Sens: sensitivity, Spec: specificity, PPV: positive predictive value, NPV: negative predictive value, PMN('s): polymorphonuclear neutrophil(s), HPF: high power field, CDC: Centers for Disease Control, HC: hemoculture.

\section{Molecular techniques}

Two studies were identified regarding molecular techniques, which are summarized in Table 3. Omar et al. [14] investigated diagnostic performance of $16 \mathrm{~S}$ rRNA PCR on swabs taken from the implant surface versus standard tissue cultures. This study provided a customized definition for FRI that was used as a reference. Only subjects undergoing revision surgery of fracture fixation devices were included. Tissue cultures were found superior to swab PCR, as a significantly higher area under the ROC curve was associated with tissue cultures. This study obtained 3 to 5 tissue samples for tissue cultures, but did not provide details on incubation time. Renz et al. [15] assessed the diagnostic performance of multiplex PCR on sonication fluid. This study applied the diagnostic criteria from the recently published consensus definition for FRI [8]. No statistically significant differences were found between tissue cultures and sonication fluid cultures or between tissue cultures and sonication fluid PCR. Specificities exceeded $90 \%$ for all tests. For tissue cultures, a minimum of 3 tissue samples was obtained. Tissue cultures were incubated for 7 days (aerobic cultures) or 14 days (anaerobic cultures). Sonication fluid cultures were incubated for 14 days (aerobic cultures as well as anaerobic cultures). Spinal implants were included in this study as well [15].

\section{Histopathology}

Three studies assessed the diagnostic accuracy of histopathology [16-18]. Results are displayed in Table 4. Simpson et al. used a customized definition for infected non-union based on clinical and microbiological results [16]. Chadayammuri et al. referred to the Centers of Disease Control definition for osteomyelitis [17]. Egol et al. did not refer to a definition for osteomyelitis [18], but referred to 
positive intraoperative cultures as the gold standard. In the study by Simpson et al., tissue cultures were incubated aerobically and anaerobically for 7 days. Histopathology criteria were provided. The authors reported a diagnostic accuracy of $91 \%$ for histopathology of fracture non-union. In cases where the diagnosis could not be determined based on microbiological and clinical criteria, histopathology proved to be a useful adjunct [16]. The second study, by Chadayammuri et al., compared the diagnostic accuracy of soft tissue histopathology with that of deep wound swab cultures, relative to open bone biopsy and culture. Soft tissue histopathology was performed in 61 out of 159 cases with post-traumatic osteomyelitis. Swab cultures were incubated aerobically and anaerobically for 5 days. No criteria or threshold values were provided for histological assessment. The authors concluded poor results regarding sensitivity and specificity for swab cultures as well as for soft tissue histopathology, relative to open bone biopsy and culture [17]. Finally, the study by Egol et al. was identified by going through reference lists. This study compared frozen section histopathology to permanent section histopathology, with 'positive intraoperative tissue culture' as the reference test. Based on this reference test, six out of 51 cases were diagnosed as infected. Histopathology criteria were provided. No information on tissue culture methods was provided, neither was the laboratory protocol to obtain frozen or permanent sections. Frozen section analysis showed poor ability to predict the presence of indolent infection. Results from permanent section histopathology were slightly better [18]. The study by Holinka et al., which is detailed in the sonication section (Table 2), looked into the diagnostic accuracy of sonication fluid cultures but included histopathology as well. The authors reported a sensitivity of $95 \%$ and a specificity of $100 \%$ for histopathology. The utilized criterion for histopathology was the presence of acute inflammation, without further specification [13]. Renz et al. included histopathology as well [15]. This study is described in more detail in the molecular techniques section of this paper (Table 3). A sensitivity and specificity of $74 \%$ and $100 \%$ was found, respectively. The authors referred to the histopathology criteria proposed by Ochsner et al., with the presence of bone necrosis, damaged soft tissue surrounding it and the penetration of microorganisms as the most prominent features for osteomyelitis [19].

\section{Discussion}

FRI is a serious complication following musculoskeletal trauma surgery. Tissue cultures are widely used as a standard diagnostic test, however, evidence for the use of tissue cultures and other tests in the diagnosis of FRI is not clear [2, 8]. This systematic review summarizes the available evidence on sonication fluid culture and tissue tests including culture, molecular diagnostics and histopathology for the diagnosis of FRI.

The first diagnostic test studied in this review was sonication fluid culture. Using low intensity ultrasound, sonication is deployed to dislodge the biofilm from the implant. The sonication fluid is then cultured onto bacterial media for further analysis. In PJI, sonication of the implant and subsequent inoculation of sonication fluid has already proven to be useful [20]. Overall, five studies addressing the diagnostic accuracy of sonication fluid cultures for FRI corresponded to the eligibility criteria and were included in this review. All five studies included tissue culture in their assessment and reported a high sensitivity for sonication fluid culture [9-13]. A statistically significant difference between sonication fluid culture and tissue culture was reported in three studies, whereby sonication fluid culture showed higher diagnostic accuracy $[10,11,13]$. Unfortunately, only one of these studies assessed these diagnostic tests separately for FRI, providing a customized definition [10] and none of these three studies was sufficiently powered to give a definitive comparison. Indeed, the study by Yano et al. is the only study that included only fracture cases and provided a custom definition for 'osteosynthesis-associated infection'. This study as well as the study by Portillo et al., Holinka et al. and Renz et al. followed the sonication protocol as it was originally described [20]. Regarding tissue samples, poor sampling methods were used in the study by Yano et al., with a requirement of 'more than one peri-implant tissue samples', while current guidelines recommend 3 to 5 or even 6 tissue samples to be taken intraoperatively [20-22]. The incubation of tissue samples in the study by Yano et al. as well as by Portillo et al. was done in accordance to current practice: cultures are generally incubated for 7 days, but there is evidence for extending the incubation period to 14 days in order to isolate less virulent anaerobic pathogens [22]. Overall, exact data on sampling methods (i.e. sampling location, transport and culture methods) was limited across studies. This is a limitation as high quality, uncontaminated, deep tissue and implant samples are essential to validate the outcome of cultures.

Free planktonic bacteria are considered to be more susceptible to antibiotic therapy than those organized in a biofilm on the implant. Therefore, in order to avoid false-negative culture results, it is generally advised to stop antimicrobial therapy two 
weeks before sampling [3, 10, 21]. In PJI, sonication fluid cultures were found superior to tissue cultures when patients received antibiotics preoperatively [20]. It seems that in patients who received antibiotics prior to surgery, sonication fluid cultures may be a useful adjunct in the diagnostic algorithm for FRI as well. Important to note is that, for the studies in this review, the sample sizes for the sub-analyses regarding preoperative antibiotics were rather small [9-11], which makes it difficult to make a statement based on these results.

Although there is no strong evidence that sonication fluid culture is superior to tissue culture in the diagnosis of FRI, it may be a useful adjunct, alongside conventional cultures. There is weak evidence that it may be helpful in patients who have received antibiotics prior to surgery. However, it has to be stated that heterogeneity in study designs, sampling and laboratory protocols make it difficult to compare results. To be able to make a definitive statement on the role of sonication in the diagnosis of FRI, future studies regarding FRI should be conducted using standardized protocols and reference criteria.

Molecular diagnostics were the second studied modality in this systematic review. Known clinical applications are the diagnoses of endocarditis and PJI, in which PCR is used as an adjunct test [2, 23-25]. Overall, it is expected that, due to its high sensitivity, PCR has the potential to detect bacteria despite antibiotic therapy. The additional advantages of PCR are short processing time $(<5 \mathrm{~h})$ and the fact that it can be fully automated [24]. On the other hand, PCR results should be interpreted cautiously due to potential false positive results [26]. This review identified one study by Omar et al. looking into the diagnostic accuracy of $16 \mathrm{~S}$ rRNA PCR for the diagnosis of FRI [14]. The authors found 16S rRNA PCR of deep wound swabs to be inferior to standard tissue cultures. In general, deep tissue swabs are not considered standard of care because they do not sufficiently represent the pathogens in the bone $[2,3$, 27]. The study by Renz et al. [15] focused on the validation of multiplex PCR on sonication fluid. The performance of sonication fluid PCR for the diagnosis of FRI was comparable to tissue culture tests. Palmer et al. published a study comparing multiplex PCR combined with mass spectrometry and FISH to conventional tissue cultures for the diagnosis of non-unions. This study did not meet our eligibility criteria as it was not a validation study. However, it did provide some interesting preliminary results: multiplex PCR with mass spectrometry identified the cases that were determined by conventional tissue cultures, but this method found additional infected cases as well. All additional cases could be confirmed by $16 \mathrm{~S}$ rRNA FISH, thereby confirming the high sensitivity of this diagnostic test [28]. With further improvement of the performance, PCR has the potential to complement conventional cultures.

Finally, we considered all articles assessing histopathology for the diagnosis of FRI. As previously published, histopathology has already proven its use in PJI $[13,15,29]$. Three studies focusing on histopathology as a diagnostic test for infected fractures were identified. The study by Simpson et al. provided evidence that histopathology of tissue within and around a fracture non-union can be a useful adjunct to standard microbiological tissue cultures [16]. The study by Chadayammuri et al. demonstrated a lower sensitivity and very low specificity [17]. However, this study has some important limitations. First of all, no criteria or thresholds, i.e. number of PMN's per HPF suggestive for infection, were provided. Secondly, they used 'open bone biopsy and culture' as the reference method, without further specification. It is not clear if this includes histopathology of bone as well. This is an important limitation as cultures can yield false positive or false negative results too. Third, they included swab cultures in their assessment, which is not a standardized technique as described above. Due to the high number of inaccuracies in this study, its outcome cannot be relied upon in clinical practice. The study by Egol et al. was identified by going through reference lists. This study showed poor results for both frozen section as well as permanent section histopathology. Little information was provided on sampling methods and it is remarkable that the reference standard for this study was a positive intraoperative tissue culture, which can yield false positive or false negative results as well. Therefore, due to these limitations, its outcome cannot be relied upon in clinical practice. Holinka et al. and Renz et al. also reported on histopathology in their studies, however, the validation of histopathology was not the primary aim in these studies and Holinka et al. included a majority of patients with prostheses. Overall, the implementation of histopathology in the diagnostic algorithm for FRI seems very interesting. The difficulty is that PMN's play an important role in the early phases of fracture healing [30]. After three to four weeks, acute inflammatory cells are less frequent and the presence of larger numbers may indicate infection. The diagnosis of early, acute fracture infections is often less problematic, with discharging wounds and virulent organisms, which are easier to culture [3]. In a recent study of FRI in cases more than four weeks from fracture, published after this search, a bimodal cut-off for the presence of PMN's provided 
encouraging results in reducing the number of cases in which the diagnosis was uncertain [31].

The limitations of this systematic review are mainly related to the previous absence of a working definition of FRI. It is essential that future evaluations of diagnostic techniques are performed in large numbers of patients and compared against an accepted definition, which includes clear clinical and microbiological criteria [8]. Studies should report the sampling method, the laboratory culture technique and number of samples cultured.

In conclusion, the presented systematic review confirms the hypothesis that scientific evidence on sonication, molecular techniques and histopathology for the diagnosis of FRI is scarce. Sonication has been extensively investigated in PJI, but the few studies on FRI are heterogeneous in design and have applied a variety of reference standards. Although these studies have shown encouraging results for sonication fluid culture, the evidence is of low quality and we cannot conclude that sonication fluid culture is superior to a good standard of tissue culture as recommended for the diagnosis of FRI. Regarding molecular techniques and histopathology, evidence is scarce and based on small studies. Further study and improvement of diagnostic performance is warranted.

\section{Supplementary Material}

Supplementary search strategy. http://www.jbji.net/v03p0173s1.pdf

\section{Competing Interests}

The authors have declared that no competing interest exists.

\section{References}

1. de Jongh MA, Bosma E, Leenen LP, Verhofstad MH. Increased consumption of hospital resources due to complications: an assessment of costs in a level I trauma center. The Journal of trauma. 2011; 71: E102-9.

2. Metsemakers WJ, Kuehl R, Moriarty TF, Richards RG, Verhofstad MH, Borens $\mathrm{O}$, et al. Infection after fracture fixation: Current surgical and microbiological concepts. Injury. 2016.

3. Trampuz A, Zimmerli W. Diagnosis and treatment of infections associated with fracture-fixation devices. Injury-Int J Care Inj. 2006; 37: 59-66.

4. Metsemakers WJ, Onsea J, Neutjens E, Steffens E, Schuermans A, McNally $M$, et al. Prevention of fracture-related infection: a multidisciplinary care package. International orthopaedics. 2017; 41: 2457-69.

5. Beaule PE, Shea B, Abedlbary H, Ahmadzai N, Skidmore B, Mallick R, et al. A protocol for a systematic review of the diagnostic accuracy of blood markers, synovial fluid, and tissue testing in periprosthetic joint infections (PJI). Systematic reviews. 2015; 4: 148.

6. Parvizi J, Jacovides C, Zmistowski B, Jung KA. Definition of periprosthetic joint infection: is there a consensus? Clinical orthopaedics and related research. 2011; 469: 3022-30.

7. Parvizi J, Zmistowski B, Berbari EF, Bauer TW, Springer BD, Della Valle $\mathrm{CJ}$, et al. New definition for periprosthetic joint infection: from the Workgroup of the Musculoskeletal Infection Society. Clinical orthopaedics and related research. 2011; 469: 2992-4.

8. Metsemakers WJ, Morgenstern M, McNally MA, Moriarty TF, McFadyen I, Scarborough M. et al. Fracture-related infection: A consensus on definition from an international expert group. Injury. 2018; 49:505-510.
9. Puig-Verdié L, Alentorn-Geli E, González-Cuevas A, Sorlí L, Salvadó M, Alier A, et al. Implant sonication increases the diagnostic accuracy of infection in patients with delayed, but not early, orthopaedic implant failure. Bone and Joint Journal. 2013; 95B: 244-9.

10. Yano MH, Klautau GB, da Silva CB, Nigro S, Avanzi O, Mercadante MT, et al. Improved diagnosis of infection associated with osteosynthesis by use of sonication of fracture fixation implants. Journal of clinical microbiology. 2014; 52: 4176-82.

11. Portillo ME, Salvado M, Trampuz A, Siverio A, Alier A, Sorli L, et al. Improved diagnosis of orthopedic implant-associated infection by inoculation of sonication fluid into blood culture bottles. Journal of clinical microbiology. 2015; 53: 1622-7.

12. Esteban J, Gomez-Barrena E, Cordero J, Martin-de-Hijas NZ, Kinnari TJ, Fernandez-Roblas R. Evaluation of quantitative analysis of cultures from sonicated retrieved orthopedic implants in diagnosis of orthopedic infection. Journal of clinical microbiology. 2008; 46: 488-92.

13. Holinka J, Bauer L, Hirschl AM, Graninger W, Windhager R, Presterl E. Sonication cultures of explanted components as an add-on test to routinely conducted microbiological diagnostics improve pathogen detection. Journal of orthopaedic research : official publication of the Orthopaedic Research Society. 2011; 29: 617-22.

14. Omar M, Suero EM, Liodakis E, Reichling M, Guenther D, Decker S, et al. Diagnostic performance of swab PCR as an alternative to tissue culture methods for diagnosing infections associated with fracture fixation devices. Injury. 2016; 47: 1421-6.

15. Renz N, Cabric S, Morgenstern C, Schuetz MA, Trampuz A. Value of PCR in sonication fluid for the diagnosis of orthopedic hardware-associated infections: Has the molecular era arrived? Injury. 2018 .

16. Simpson A, Wood MK, Athanasou NA. Histological assessment of the presence or absence of infection in fracture non-union. Injury-Int J Care Inj. 2002; 33: 151-5.

17. Chadayammuri V, Herbert B, Hao J, Mavrogenis A, Quispe JC, Kim JW, et al. Diagnostic accuracy of various modalities relative to open bone biopsy for detection of long bone posttraumatic osteomyelitis. European Journal of Orthopaedic Surgery and Traumatology. 2017; 27: 871-5.

18. Egol KA, Karunakar MA, Marroum MC, Sims SH, Kellam JF, Bosse MJ. Detection of indolent infection at the time of revision fracture surgery. The Journal of trauma. 2002; 52: 1198-201.

19. Ochsner PE, Hailemariam S. Histology of osteosynthesis associated bone infection. Injury. 2006; 37 Suppl 2: S49-58.

20. Trampuz A, Piper KE, Jacobson MJ, Hanssen AD, Unni KK, Osmon DR, et al. Sonication of removed hip and knee prostheses for diagnosis of infection. The New England journal of medicine. 2007; 357: 654-63.

21. Atkins BL, Athanasou N, Deeks JJ, Crook DW, Simpson H, Peto TE, et al. Prospective evaluation of criteria for microbiological diagnosis of prosthetic-joint infection at revision arthroplasty. The OSIRIS Collaborative Study Group. Journal of clinical microbiology. 1998; 36: 2932-9.

22. NHS. Investigation of orthopaedic implant associated infections. In: Services SUM, editor.; 2016. p. 1-35.

23. Rovery C, Greub G, Lepidi H, Casalta JP, Habib G, Collart F, et al. PCR detection of bacteria on cardiac valves of patients with treated bacterial endocarditis. Journal of clinical microbiology. 2005; 43: 163-7.

24. Hischebeth GTR, Randau TM, Buhr JK, Wimmer MD, Hoerauf A, Molitor E, et al. Unyvero i60 implant and tissue infection (ITI) multiplex PCR system in diagnosing periprosthetic joint infection. Journal of Microbiological Methods. 2016; 121: 27-32.

25. Marin M, Garcia-Lechuz JM, Alonso P, Villanueva M, Alcala L, Gimeno $\mathrm{M}$, et al. Role of universal 16S rRNA gene PCR and sequencing in diagnosis of prosthetic joint infection. Journal of clinical microbiology. 2012; 50: 583-9.

26. Panousis K, Grigoris P, Butcher I, Rana B, Reilly JH, Hamblen DL. Poor predictive value of broad-range PCR for the detection of arthroplasty infection in 92 cases. Acta orthopaedica. 2005; 76: 341-6.

27. Aggarwal VK, Higuera C, Deirmengian G, Parvizi J, Austin MS. Swab cultures are not as effective as tissue cultures for diagnosis of periprosthetic joint infection. Clinical orthopaedics and related research. 2013; 471: 3196-203.

28. Palmer MP, Altman DT, Altman GT, Sewecke JJ, Ehrlich GD, Hu FZ, et al. Can we trust intraoperative culture results in nonunions? Journal of orthopaedic trauma. 2014; 28: 384-90.

29. Krenn V, Morawietz L, Perino G, Kienapfel H, Ascherl R, Hassenpflug GJ, et al. Revised histopathological consensus classification of joint implant related pathology. Pathology, research and practice. 2014; 210: 779-86.

30. El-Jawhari JJ, Jones E, Giannoudis PV. The roles of immune cells in bone healing; what we know, do not know and future perspectives. Injury. 2016; 47: 2399-406. 
31. Morgenstern M, Athanasou N, Ferguson J, Metsemakers WJ, Atkins B, McNally M. The value of quantitative histology in the diagnosis of fracture-related infection. Bone and Joint Journal. 2018: In Press. 